\title{
Ischemic Brain Injury in Hyperhomocysteinemia
}

\author{
Jan Lehotsky ${ }^{1}$ • Maria Kovalska² • Eva Baranovicova ${ }^{3} \bullet$ Petra Hnilicova $^{3}$ • \\ Dagmar Kalenska ${ }^{1,4} \bullet$ Peter Kaplan ${ }^{1}$
}

${ }^{1}$ Department of Medical Biochemistry, Jessenius Faculty of Medicine in Martin, Comenius University in Bratislava, Mala Hora, Martin, Slovakia; ${ }^{2}$ Department of Histology and Embryology, Jessenius Faculty of Medicine in Martin, Comenius University in Bratislava, Mala Hora, Martin, Slovakia; ${ }^{3}$ BioMed Martin, Jessenius Faculty of Medicine in Martin, Comenius University in Bratislava, Mala Hora, Martin, Slovakia; ${ }^{4}$ Department of Anatomy, Jessenius Faculty of Medicine in Martin, Comenius University in Bratislava, Mala Hora, Martin, Slovakia

Author for correspondence: Jan Lehotsky, Department of Medical Biochemistry, Jessenius Faculty of Medicine in Martin, Comenius University in Bratislava, Mala Hora, Martin, Slovakia. Email: jan.lehotsky@uniba.sk

Cite this chapter as: Lehotsky J, Kovalska M, Baranovicova E, Hnilicova P, Kalenska D, Kaplan P. Ischemic Brain Injury in Hyperhomocysteinemia. In: Pluta R, editor. Cerebral Ischemia. Brisbane (AU): Exon Publications; 2021. Online first Sep 10.

Doi: https://doi.org/10.36255/exonpublications.cerebralischemia.2021.

hyperhomocysteinemia

Abstract: Homocysteine is an intermediate product of methionine metabolism.
Hyperhomocysteinemia can be caused by high intake of methionine, deficiency of
vitamin $\mathrm{B}_{12}$, folate, or both. Hyperhomocysteinemia causes cardio- and cerebro-
vascular diseases, including ischemic stroke. Hyperhomocysteinemia-induced
oxidative stress, inflammation, and endoplasmic reticulum stress play an impor-
tant role in the pathogenesis of several neurodegenerative diseases. Pyramidal
neurons of the hippocampus are sensitive to prolonged levels of homocysteine
due to the absence of metabolization by transsulfuration as well as by folate- or

In: Cerebral Ischemia. Pluta R (Editor). Exon Publications, Brisbane, Australia. ISBN: 978-0-6450017-9-2; Doi: https://doi.org/10.36255/exonpublications. cerebralischemia.2021

Copyright: The Authors.

License: This open access article is licenced under Creative Commons Attribution-NonCommercial 4.0 International (CC BY-NC 4.0) https://creativecommons.org/licenses/by-nc/4.0/ 
$\mathrm{B}_{12}$-dependent remethylation. This chapter highlights the role of hyperhomocysteinemia in neurodegenerative changes following cerebral ischemia. An overview of how hyperhomocysteinemia by itself, or in combination with ischemiareperfusion injury, exacerbates neurodegeneration is presented. The role of hyperhomocysteinemia in amyloid deposition and hyperphosphorylation of tau protein in the brain, along with plasma metabolic alterations in cerebral ischemiareperfusion injury is reviewed. Prevention of hyperhomocysteinemia may have therapeutic implications in cerebral ischemic stroke and deserves investigation.

Keywords: cerebral ischemia-reperfusion injury; homocysteine; ischemic brain injury; methionine; hyperhomocysteinemia

\section{INTRODUCTION}

Many experimental and clinical studies show that co-morbid disorders are risk factors for developing vascular pathologies, such as stroke, in humans (1,2). Mild hyperhomocysteinemia ( $\mathrm{hHcy}$ ) may increase the risk of stroke, probably due to the pleiotropic biochemical properties of homocysteine (Hcy) $(2,3)$. Hcy, a critical component of the one-carbon methionine (Met) metabolism, has been proposed to be an etiological agent of cerebrovascular disorders, such as ischemic stroke $(2-4)$. Its toxicity is the result of auto-oxidation and free radical generation $(3,5)$. Intermediates of Hcy metabolism include Hcy-thiolactone and homocysteic acid. Increased lipoprotein and protein oxidation are directly involved in neuronal degeneration $(6,7)$. Posttranslational modifications of proteins, homocysteinylation, and thiolation result in the impairment of functional proteins and enzyme inactivation (6). Overstimulation of the NMDA (N-Methyl-D-aspartic acid or N-Methyl-D-aspartate) and metabotropic receptors (mGluR), and the reduction of glutamate uptake in the cortex (8) and hippocampus (9), induce impairment of neuronal functions and the damage of glial cells $(5,10)$.

Cerebral ischemia induces neural damage through the depletion of cellular energy, release of excitatory amino acids, induction of mitochondrial dysfunction, and excessive generation of reactive oxygen (ROS) and nitrogen (RNS) species $(7,11)$. Preconditioning is one of the recognized neuroprotective strategies in which a period of sublethal insult (ischemia-ischemic preconditioning [IPC]) induces robust protection (tolerance) against subsequent injurious/lethal ischemic events $(7,11)$. The clinical relevance of hHcy in the development of human stroke and the toxicity of hHcy in the brain has been reported (11-13).

Met is an essential amino acid present in food $(14,15)$. Intake of diet rich in Met, or the dysregulation of Met metabolism in the "Met-Hcy" cycle, can lead to the elevation of Hcy in plasma. S-adenosyl homocysteine (SAH), an intermediate of metabolic conversion of Hcy, regulates methylation signalling, and causes hypomethylation of DNA and proteins (16). Cellular clearance of Hcy is essential for genetic protection. Subcutaneous administration of Hcy in rats lead to mild hHcy, causes disintegration of neuronal tissue in the cortex and hippocampus, and triggers epigenetic changes via impairment in histone acetylation, likely by hHcy-initiated DNA hypomethylation (17-20). Met-rich diet induces pathological changes in the CAl hippocampal area of rats. 


\section{NEUROTOXICITY OF HOMOCYSTEINE}

Epigenetic mechanisms, such as DNA methylation, RNA editing, noncoding RNAs (ncRNAs), and microRNAs (miRNAs) are involved in the pathogenesis of ischemic stroke (13). Hcy is toxic to neuronal and endothelial cells (3, 4). A link between hHcy and vascular diseases, cardiovascular symptoms, and neurological disorders such as cerebral atrophy and seizures has been recognized (21-23). Metabolic conversion of Hcy requires the presence of dietary vitamin $\mathrm{B}_{12}$ (cobalamin) and folic acid for methyl group transfer and re-methylation of N-5methyltetrahydrofolate-Hcy methyltransferase activity. Transsulfuration reaction of Hcy depends on the presence of vitamin $\mathrm{B}_{6}$. The reaction is absent in the brain, and thus, the remethylation pathway depends on exogenous folate and cobalamin. This fact has clinical relevance due to the lower intake of vitamins in older age, decreased absorption by the gastrointestinal mucosa, or low stores of vitamin $B_{12}$ in the brain. The neurotoxicity of Hcy affects neuronal survival, the ability of neurons to transmit signals, and alters neural networks and circuitry $(24,25)$. Hcy can be transported through the blood-brain barrier via a specific saturable transporter, and accumulate in the brain (4). It induces dysfunction of endothelial, astrocytic, and neuronal cells in brain $(3,24)$. In the hippocampus, hHcy induces lipoperoxidation, apoptosis, and neuronal degeneration (3, 7, 11, 26-28). In the cortex, secretary pathway calcium-ATPase 2 and $\mathrm{Mn}^{2+}$ superoxide dismutase activity are reduced (26) and Golgi stress is increased because of redox dysbalance $(3,29,30)$. hHcy reduces mitochondrial respiration, increases the electron transport chain complex II, and inhibits complex IV activity (31). It also induces a decline in electron transport chain activities of the heart through the expression of proteins responsible for cellular stress response and redox balance (32).

Met plays a critical role in cell physiology (33). Its plasma level is the result of Met metabolism, daily intake, and protein degradation (34). An excess of Met could be detrimental and might increase the risk of developing several diseases, including toxicity to central nervous system, DNA and dendritic spine density damage, and synaptic remodeling $(33,35)$. Faulty Met metabolism results in the accumulation of its metabolites in plasma, mostly Hcy, as part of the Met-Hcy cycle. If high dietary intake of Met exceeds the transsulfuration capacity, the Hcy blood concentration increases $(15,33)$. Data suggest that hHcy caused by Met diet leads to neuroinflammation, microhemorrhages, apoptosis, and synaptic remodeling $(33,35,36)$. Furthermore, modifications in the "one-carbon metabolism" may exacerbate the toxic potential of Hcy and its metabolites, and affect the "methylation index" with an impact on gene regulation $(16,33,35)$. In our studies, a high-Met diet induced neuropathological changes in the CA1 hippocampal area and impaired spatial and learning memory acquisition-likely due to Met-induced changes in "methylation index" of hippocampus and participation in the Met-Hcy cycle (37). ${ }^{1} \mathrm{H}$ NMR spectroscopy with 7T MR scanner showed alterations in metabolic profile, increased hippocampal volume, and modifications in the number and morphology of astrocytes and neurons of CA1 hippocampus $(20,37)$. Subcutaneous injection of Hcy in rats led to neurodegeneration, altered morphology of the hippocampus, entorhinal, parietal and motor cortex, and accumulation of amyloid plaques and hyperphosphorylated tau protein $(18,38,39)$. Met diet also increases $\mathrm{H}_{2} \mathrm{~S}$ production 
and inflammatory factors, and decreases mitochondrial function (40). High-Met diet-induced mild hHcy $(20,33,41-43)$ can cause vascular cognitive impairment, neuroinflammation, and tau protein phosphorylation $(44,45)$. These can in turn affect astrocytes, microglia, and neurons (17, 18, 20, 42, 46). Gestational, neonatal, or adult hMet in rats and mice increases autophagosomes, apoptosis, and caspase activity $(35,47)$.

NMR metabolomic analysis of plasma showed alteration in energy metabolism in rats treated with Met diet (37). Decreased utilization of glucose is balanced with increased utilization of triacylglycerols to coordinate cellular function and facilitate neuronal survival (48-50) and compensate abnormalities in behavioral tests $(33,48)$. Because memory impairment is frequently the earliest symptom of dementia $(51,52)$, we hypothesize that Met induces neuropathological changes in the hippocampus which leads to memory impairment at the very early stages of Met/Hcy neurotoxicity. The clinical relevance is that a diet, which is high in Met and low in B vitamins, is a risk factor for the development of human neurodegenerative disorders.

\section{HYPERHOMOCYSTEINEMIA AS A DETRIMENTAL FACTOR IN CEREBRAL ISCHEMIA-REPERFUSION INJURY}

Apart from being neurotoxic by itself, hHcy exerts synergistic detrimental toxicity in cerebral ischemic experimental models of human stroke (Figure 1) (53). Ischemia-reperfusion injury (IRI) induces degeneration of hippocampal neurons $(17,54)$. The synergistic effect of both stressors, hHcy and IRI, leads to the aggravation of neuronal and glial morphological changes in the hippocampus and the cortex $(17,42,54)$. Astrocytes, as dynamic cells, affect intercellular communication with surrounding synapses $(10,55)$. The synergisitc effect of ischemia and hHcy modifies the expression of the mitogen-activated kinase $(17,54,56)$ and enhances the severity of tissue injury $(12,57)$. hHcy aggravates cortical cell injury after ischemia via autophagy, blood-brain barrier disruption, and homocysteinylation of cytochrome c, which in turn induces autophagy (58). Hcy reduces the number of reparatory endothelial cells in stroke patients (59), silences coagulation genes by hypermethylation (60), activates dysregulation of the ubiquitin system (61), and suppresses NO synthesis to impair circulation (62). Hypermethioninemia (hMet) is linked to memory deficits and morphological changes in the hippocampus (63). Chronic hMet and its sulfoxide product, induces oxidative stress (64) and contributes to brain pathology (65).

Combination of hHcy and IRI aggravates the neurodegenerative processes and might eventually lead to the development of Alzheimer's disease-like neuropathology $(18,38)$. In rats that were fed a high-Met diet, IRI further increased Hcy levels, aggravated the degeneration of the hippocampal neurons, decreased grey matter volume, and altered the metabolic ratio $(42,47)$. Furthermore, many studies have shown the deleterious role of hHcy on cognition and cerebral microbleeds $(45,66-70)$.

Astrocytes activation can precede neuronal loss and aggravate ischemiainduced brain injury (71). In animals fed Met diet and subjected to IRI, short, thicker, and branched processes of astrocytes were found $(20,72)$. 


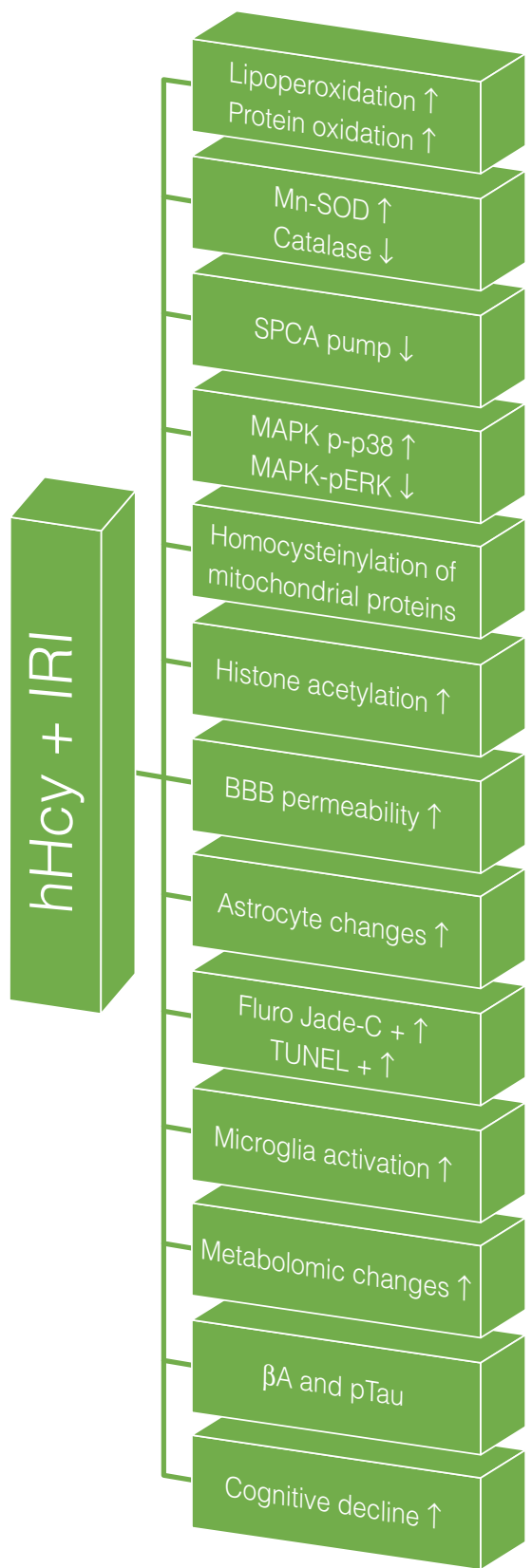

Figure 1. Mechanisms leading to the neurotoxicity in hHcy + IRI conditions. hHcy+IRI-mediated neurotoxicity is the result of a plethora of dysregulated pathways including redox dysbalance, lipoperoxidation, protein oxidation, secretory pathway $\mathrm{Ca}^{2+} / \mathrm{Mn}^{2+}$-ATPase, and p38 MAPK. Together, they cause neurodegeneration through a variety of mechanisms including the induction of apoptosis, disruption of the blood brain barrier, $\beta$ amyloid and Tau accumulation, and alterations in metabolome. $(\uparrow)$, increased number of cells and/or activity; $(\downarrow)$, decreased number of cells and/or activity. $\beta A$, beta amyloid; BBB, blood-brain barrier; pTau, phosphorylated tau protein $(3,5,7,10,15,17-20,26,28,37-43,46,53,54,58,62)$. 
Other studies demonstrate neuroinflammatory and neurodegenerative changes in various neuronal cell types $(42,73,74)$. A time-dependent decrease of the tNAA/tCr ratio ( $\mathrm{N}$-acetylaspartate/total creatine [marker of metabolic alterations]) was also observed following IRI $(37,42,70,75)$. Choline, considered a marker of membrane integrity (76), i.e., phospholipids synthesis and degradation, suggests the process of hippocampal re/de-myelination. An increased ratio of mlns/tCr (myo-Inositol [mIns]), total creatine [tCreatine]), suggests changes in the number and morphology of hippocampal astrocytes and the process of de-myelination $(75,77)$. Collectively, the results of metabolic analysis indicate that IRI with Met diet initiates progressive metabolic disturbances with the dysregulation of the myelinated tract in the hippocampus (42). While hHcy alone leads to an increase in the hippocampal volume $(20,42)$, in conjunction with IRI, it further increases cerebral edema on day 3 , followed by a decrease on day 7 -probably a sign of neurodegeneration $(69,78,79)$. Sustained edema results from the blood-brain barrier disruption caused by hHcy, or its metabolites, or the excitotoxic effect of Hcy $(47,62)$. Most of the blood-brain barrier damage usually occurs before $48 \mathrm{~h}$ post-stroke, as shown in the embolic ischemic model in rats $(69,78)$. Studies also suggest that mild hHcy impairs cardiac contractility, alters metabolism, and causes cardiac muscle remodeling and dysfunction $(32,80)$, and abnormally activated MMP-9 (81). Collectively, a mild hHcy in combination with IRI generates a toxic environment with detrimental impact on neuronal tissue, volume disturbances, attenuated neurites, and activation of astrocytes in hippocampus (42).

Hypoxic or ischemic preconditioning is a widely recognized strategy that eventually leads to ischemic tolerance $(82,83)$. As discussed above, ischemiareperfusion injury leads to neurodegeneration of hippocampal neurons in the CAl region (46). Preconditioning remarkably reduces neurodegeration and confers neuroprotection $(17,28,54)$. The combination of hHcy with ischemic injury further increases the extent of neurodegeneration, and preconditioning suppresses neuronal degeneration $(3,7,17,26,28)$. Combination of both stressors (ischemia+hHcy) leads to the massive activation of phospho-p38 MAPK (17). A recent study (83), using NMR to assess metabolomic changes in rat plasma, showed disturbed glycolysis pathway, and increased ketone bodies along with increased utilization of triacylglycerols. A decreased level of glycolytic intermediates (lactate, pyruvate, acetate) with an increased glucose was found in ischemic and preconditioned animals (83). HHcy also induced alterations in intracellular signaling, epigenetic dysregulation in methylation or acetylation status, microRNAs $(13,84,85)$, and one-carbon metabolism, as part of Hcy metabolism $(3,5,13,84)$. Remarkably, demethylation of SAM (S-adenosylmethionine) to SAH is the sole source of de novo methyl groups for the cell. Thus, in hHcy conditions, dysregulation of this step might have an implication for many cellular processes, including modulation of gene expression via epigenetic regulation $(13,84)$. Collectively, responses of neuronal cells to hHcy, IRI, and preischemic challenge in rats suggest a correlation of several etiological factors, such as antioxidant defense (3), alterations in the mechanisms of $\mathrm{Ca}^{+}$transport (26), DNA methylation, and chromatin remodeling. In summary, the combination of hHcy with ischemic injury increases the extent of neurodegeneration and preconditioning reduces neuronal degeneration $(3,7,17,26,28,83)$. 


\section{CONCLUSION}

The prevalence of hHcy and its role in the pathogenesis of cerebrovascular disorders is still not fully explored. hHcy has a role in the etiology of neurological damages due to its toxic effect on neurons, glia and vascular endothelium. Furthermore, hHcy can cause hippocampal edema, metabolic depletion, and cognitive decline, which is subsequently exacerbated by ischemia-reperfusion insult. However, most of our current knowledge is largely based on experimental findings and strategies to decrease plasma Hcy level did not reach conclusive clinical outcomes $(6,66,86)$. The efficacy of combined folic acid, $\mathrm{B}_{6}$, and $\mathrm{B}_{12}$-vitamin supplementation to reduce hHcy is clinically inconclusive. Prevention of hHcy has the potential to prevent human stroke and Alzheimer's disease incidence, and deserves further investigation. Epigenetic DNA methylation as a consequence of hHcy by endogenous (polymorphism of Hcy and folate pathways genes) and/or exogenous factors (dietary Met intake or/and deficiency of folate and vitamins) might be involved in hHcy pathogenesis. Exploration of the methyl balance and understanding the pathophysiology of diseases from a "methylation point of view", although challenging, is a worthwhile effort.

Acknowledgment: The authors acknowledge the financial support from grant VEGA, No : 1/0230/20 and APVV, grant No. 15/107.

Conflict of Interest: The authors declare no potential conflicts of interest concerning research, authorship, and/or publication of this chapter.

Copyright and Permission Statement: To the best of our knowledge, the materials included in this chapter do not violate copyright laws. All sources have been appropriately acknowledged and/or referenced. Where relevant, appropriate permissions have been obtained from the original copyright holder(s).

\section{REFERENCES}

1. Lehotský J, Burda J, Danielisová V, Gottlieb M, Kaplán P, Sániová B. Ischemic tolerance: the mechanisms of neuroprotective strategy. Anat Rec. 2009;292:2002-2012. https://doi.org/10.1002/ $\operatorname{ar} 20970$

2. Kwon HM, Lee YS, Bae HJ, Kang DW. Homocysteine as a predictor of early neurological deterioration in acute ischemic stroke. Stroke. 2014;45(3):871-3. https://doi.org/10.1161/ STROKEAHA. 113.004099

3. Petras M, Tatarkova Z, Kovalska M, Mokra D, Dobrota D, Lehotsky J, et al. Hyperhomocysteinemia as a risk factor for the neuronal system disorders. J Physiol Pharmacol. 2014;65:15-23.

4. Herrmann W, Obeid R. Homocysteine: a biomarker in neurodegenerative diseases. Clin Chem Lab Med. 2011;49:435-441. https://doi.org/10.1515/CCLM.2011.084

5. Lehotský J, Tóthová B, Kovalská M, Dobrota D, Beňová A, Kalenská, D, et al. Role of Homocysteine in the Ischemic Stroke and Development of Ischemic Tolerance. Front. Neurosci. 2016;10:538. https:// doi.org/10.3389/fnins.2016.00538

6. Jakubowski H. Homocysteine in Protein Structure/Function and Human Disease - Chemical Biology of Homocysteine-containing Proteins. Springer-Verlag, Wien. 2013; pp. 166. https://doi. org/10.1007/978-3-7091-1410-0 
7. Lehotsky J, Petras M, Kovalska M, Tothova B, Drgova H, Kaplan P. Mechanisms involved in the ischemic tolerance in brain: effect of the homocysteine. Cell Mol Neurobiol. 2015;35:7-15. https://doi. org/10.1007/s10571-014-0112-3

8. da Cunha MJ, da Cunha AA, Ferreira AG, Machado FR, Schmitz, Lima DD et al. Physical exercise reverses glutamate uptake and oxidative stress effects of chronic homocysteine administration in the rat. Int Dev Neurosci. 2012;30:69-74. https://doi.org/10.1016/j.ijdevneu.2012.01.001

9. Machado NJ, Simões AP, Silva HB, Ardais AP, Kaster MP, Garção P, et al. Caffeine reverts memory but not mood impairment in a depression-prone mouse strain with up-regulated adenosine A2A receptor in hippocampal glutamate synapses. Mol Neurobiol. 2017;54:1552-1563. https://doi.org/10.1007/ s12035-016-9774-9

10. Škovierová H, Mahmood, S, Blahovcová E, Hatok J, Lehotský J, Murín R. Effect of homocysteine on survival of human glial cells. Physiol Res. 2015;64:747-754. https://doi.org/10.33549/ physiolres.932897

11. Gidday JM. Cerebrovascular ischemic protection by pre- and post-conditioning. Brain Circ. 2015; 1:97-103. https://doi.org/10.4103/2394-8108.166379

12. Poddar R, Paul S. Novel crosstalk between ERK MAPK and p38 MAPK leads to 41 homocysteineNMDA receptor-mediated neuronal cell death. J. Neurochem. 2013;124:558-570. https://doi. org/10.1111/jnc. 12102

13. Kalani A, Kamat PK, Familtseva A, Chaturvedi P, Muradashvili N, Narayanan N, Tyagi SC, Tyagi N. Role of microRNA29b in blood-brain barrier dysfunction during hyperhomocysteinemia: an epigenetic mechanism. J Cereb Blood Flow Metab. 2014;34, 1212-1222. https://doi.org/10.1038/ jcbfm.2014.74

14. Liu B, Ma S, Wang T, Zhao C, Li Y, Yin J, et al. A novel rat model of heart failure induced by high methionine diet showing evidence of association between hyperhomocysteinemia and activation of NF-kappaB. Am J Transl Res. 2016;8(1):117-124.

15. Lehotsky J, Kovalska M, Tomascova A, Kalenska D, Baranovicova E, Kaplan P. Ischemic brain injury in hyperhomocysteinemic conditions and the development of Alzheimer's disease. In: Pluta R. Brain ischemia: Alzheimer's disease mechanisms. New York: Nova Science Publishers, Inc.; 2019. pp. 115-156.

16. Shen W, Gao C, Cueto R, Liu L, Fu H, Shao Y, et al. Homocysteine-methionine cycle is a metabolic sensor system controlling methylation-regulated pathological signalling. Redox Biology. 2020;28:101322. https://doi.org/10.1016/j.redox.2019.101322

17. Kovalska M, Kovalska L, Tothova B, Mahmood S, Adamkov M, Lehotsky J. Combination of hyperhomocysteinemia and ischemic tolerance in experimental model of global ischemia in rats. J Physiol Pharmacol. 2015;66:887-897.

18. Kovalska M, Tothova B, Kovalska L, Tatarkova Z, Kalenska D, Tomascova A, et al. . Association of Induced Hyperhomocysteinemia with 'Alzheimer's Disease-Like Neurodegeneration in Rat Cortical Neurons After Global Ischemia-Reperfusion Injury. Neurochem Res. 2018;43(9):1766-1778. https:// doi.org/10.1007/s11064-018-2592-x

19. Tóthová B, Kovalská M, Kalenská D, Tomašcová A, Lehotský J. Histone Hyperacetylation as a Response to Global Brain Ischemia Associated with Hyperhomocysteinemia in Rats. Int J Mol Sci. 2018;19:3147. https://doi.org/10.3390/ijms19103147

20. Kovalska M, Hnilicova P, Kalenska D, Tothova B, Adamkov M, Lehotsky J. Effect of Methionine Diet on Metabolic and Histopathological Changes of Rat Hippocampus. Int J Mol Sci. 2019;20(24):6234. https://doi.org/10.3390/ijms20246234

21. Jakubowski H, Perla-Kaján J, Finnell RH, Cabrera RM, Wang H, Gupta S, et al. Genetic or nutritional disorders in homocysteine or folate metabolism increase protein N-homocysteinylation in mice. FASEB J. 2009;23:1721-1727. https://doi.org/10.1096/fj.08-127548

22. Durand P, Prost M, Loreau N, Lussier-Cacan S, Blache D. Impaired Homocysteine Metabolism and Atherothrombotic Disease. Lab Invest. 2001;81:645-672. https://doi.org/10.1038/labinvest.3780275

23. Obeid R, Herrmann W. Mechanisms of homocysteine neurotoxicity in neurodegenerative diseases with special reference to dementia. FEBS Lett. 2006;580:2994-3005. https://doi.org/10.1016/j. febslet.2006.04.088 
24. Boldyrev A, Bryushkova E, Mashkina A, Vladychenskaya E. Why is homocysteine toxic for the nervous and immune systems? Curr Aging Sci. 2013;6:29-36. https://doi.org/10.2174/1874609811205 9990007

25. Chen S, Dong Z, Zhao Y, Sai N, Wang X, Liu H, Huang G, Zhang X. Homocysteine induces mitochondrial dysfunction involving the crosstalk between oxidative stress and mitochondrial pSTAT3 in rat ischemic brain. Sci Rep. 2017a;7(1):6932. https://doi.org/10.1038/s41598-017-07112-z

26. Pavlikova M, Kovalska M, Tatarkova Z, Sivonova-Kmetova M, Kaplan P, Lehotsky J. Response of secretory pathways Ca2+ ATPase gene expression to hyperhomocysteinemia and/or ischemic preconditioning in rat cerebral cortex and hippocampus. Gen Physiol Biophys. 2011;30:61-69. https://doi. org/10.4149/gpb_2011_SI1_61

27. Kolling J, Scherer EB, Siebert C, Longoni A, Loureiro S, Weis S, et al.. Severe hyperhomocysteinemia decreases respiratory enzyme and $\mathrm{Na}(+)-\mathrm{K}(+)$ ATPase activities, and leads to mitochondrial alterations in rat amygdala. Neurotox Res. 2016;29:408-418. https://doi.org/10.1007/s12640-015-9587-z

28. Kovalska M, Kovalska L, Mikuskova K, Adamkov M, Tatarkova, Z, Lehotsky J. p-ERK involvement in the neuroprotection exerted by ischemic preconditioning in rat hippocampus subjected to four vessel occlusion. J Physiol Pharmacol. 2014;65:767-776.

29. Sepúlveda MR, Marcos D, Berrocal M, Raeymaekers L, Mata AM, Wuytack F. Activity and localization of the secretory pathway $\mathrm{Ca} 2+$ ATPase isoform 1 (SPCA1) in different areas of the mouse brain during postnatal development. Mol Cell Neurosci. 2008;38:461-473. https://doi.org/10.1016/j.mcn.2008.02.012

30. Longoni A, Kolling J, Dos Santos TM, Dos Santos JP, da Silva JS, Pettenuzzo L, et al. 1,25Dihydroxyvitamin D3 exerts neuroprotective effects in an ex vivo model of mild hyperhomocysteinemia. Int J Dev Neurosci. 2016;48:71-79. https://doi.org/10.1016/j.ijdevneu.2015.11.005

31. Chang L, Geng B, Yu F, Zhao J, Jiang H, Du J, et al. Hydrogen sulfide inhibits myocardial injury induced by homocysteine in rats. Amino Acids. 2008;34:573-585. https://doi.org/10.1007/ s00726-007-0011-8

32. Timkova V, Tatarkova Z, Lehotsky J, Racay P, Dobrota D, Kaplan P. Effects of mild hyperhomocysteinemia on electron transport chain complexes, oxidative stress, and protein expression in rat cardiac mitochondria. Mol Cell Biochem. 2016;411:261-270. https://doi.org/10.1007/s11010-015-2588-7

33. Tapia-Rojas C, Lindsay CB, Montecinos-Oliva C, Arrazola MS, Retamales RM, Bunout D, et al. Is L-methionine a trigger factor for Alzheimer's-like neurodegeneration?: Changes in A $\beta$ oligomers, tau phosphorylation, synaptic proteins, Wnt signaling and behavioral impairment in wild-type mice. Mol Neurodegener. 2015;10:62. https://doi.org/10.1186/s13024-015-0057-0

34. Stabler SP, Steegborn C, Wahl MC, Oliveriusova J, Kraus JP, Allen RH, et al. . Elevated plasma total homocysteine in severe methionine adenosyltransferase I/III deficiency. Metabolism. 2002; 5l(8):981-8. https://doi.org/10.1053/meta.2002.34017

35. Zhang JW, Ma YM, Jing L, Wang YL, Zhang JZ. Synaptic remodeling and reduced expression of the transcription factors, HES1 and HES5, in the cortex neurons of cognitively impaired hyperhomocysteinemic mice. Pathol Res Pract. 2020;216(6):152953. https://doi.org/10.1016/j.prp.2020.152953

36. Tchantchou F, Goodfellow M, Li F, Ramsue L, Miller C, Puche A, Fiskum G. HyperhomocysteinemiaInduced Oxidative Stress Exacerbates Cortical Traumatic Brain Injury Outcomes in Rats. Cell Mol Neurobiol. 2021;41(3):487-503. https://doi.org/10.1007/s10571-020-00866-7

37. Kovalska M, Baranovicova E, Kalenska D, Tomascova A, Adamkov M, Kovalska L, et al. Methionine Diet Evoked Hyperhomocysteinemia Causes Hippocampal Alterations, Metabolomics Plasma Changes and Behavioral Pattern in Wild Type Rats. Int J Mol Sci. 2021;22(9):4961. https://doi.org/10.3390/ ijms22094961

38. Kovalska M, Tothova B, Kalenska D, Tomascova A, Kovalska L, Adamkov M, et al. Association of induced hyperhomocysteinemia with neurodegeneration in rat entorhinal cortex-hippocampal system after global brain ischemia: A progression of Alzheimer's disease-like pathological features? Activitas Nervosa Superior Rediviva. 2019a;61(1):31-38.

39. Petráš M, Drgová A, Kovalská M, Tatarková Z, Tóthová B, Križanová O, et al. Effect of Hyperhomocysteinemia on Redox Balance and Redox Defence Enzymes in Ischemia-Reperfusion Injury and/or After Ischemic Preconditioning in Rats. Cell Mol Neurobiol. 2017;37(8):1417-31. https://doi.org/10.1007/s10571-017-0473-5 
40. Ji Y, Li Y, Zhao Z, Li P, Xie Y. Hydrogen Sulfide Overproduction Is Involved in Acute Ischemic Cerebral Injury Under Hyperhomocysteinemia. Frontiers in neuroscience. 2020;14:582851. https://doi.org/ 10.3389/fnins.2020.582851

41. Tóthová B, Kovalská M, Kalenská D, Beňová A, Lehotský J. Effect of methionine-induced hyperhomocysteinemia on neurodegeneration in experimental conditions. Act Nerv Super Rediviva. 2017;59(2):101-107.

42. Kovalska M, Hnilicova P, Kalenska D, Tomascova A, Adamkov M, Lehotsky J. Effect of Methionine Diet on Time-Related Metabolic and Histopathological Changes of Rat Hippocampus in the Model of Global Brain Ischemia. Biomolecules. 2020;10:1128. https://doi.org/10.3390/bioml0081128

43. Wang L, Ren B, Hui Y, et al. Methionine Restriction Regulates Cognitive Function in High-Fat DietFed Mice: Roles of Diurnal Rhythms of SCFAs Producing- and Inflammation-Related Microbes. Mol Nutr Food Res. 2020;64(17): 2000190. https://doi.org/10.1002/mnfr.202000190

44. Sudduth TL, Weekman EM, Price BR, Gooch JL, Woolums A, Norris CM, Wilcock DM. Time-course of glial changes in the hyperhomocysteinemia model of vascular cognitive impairment and dementia (VCID). Neuroscience. 2017;341:42-51. https://doi.org/10.1016/j.neuroscience.2016.11.024

45. Weekman EM, Sudduth TL, Price BR, Woolums AE, Hawthotne D, Seaks CE, Wilcock DM. Time course of neuropathological events in hyperhomocysteinemic amyloid depositing mice reveals early neuroinflammatory changes that precede amyloid changes and cerebrovascular events. J Neuroinflammation. 2019;16(1):284. https://doi.org/10.1186/s12974-019-1685-z

46. Seminotti B, Zanatta Â, Ribeiro RT, da Rosa MS, Wyse AT, Leipnitz G, et al. Disruption of Brain Redox Homeostasis, Microglia Activation and Neuronal Damage Induced by Intracerebroventricular Administration of S-Adenosylmethionine to Developing Rats. Mol Neurobiol. 2019;56(4):2760-2773. https://doi.org/10.1007/s12035-018-1275-6

47. de S Moreira D, Figueiró PW, Siebert C, Prezzi CA, Rohden F, Guma FCR, et al. Chronic Mild Hyperhomocysteinemia Alters Inflammatory and Oxidative/Nitrative Status and Causes Protein/DNA Damage, as well as Ultrastructural Changes in Cerebral Cortex: Is Acetylsalicylic Acid Neuroprotective? Neurotox Res. 2018;33(3):580-592. https://doi.org/10.1007/s12640-017-9847-1

48. Ruan HB, Crawford PA. Ketone bodies as epigenetic modifiers. Curr Opin Clin Nutr Metab Care. 2018;21:260-266. https://doi.org/10.1097/MCO.0000000000000475

49. Su X, Wellen KE, Rabinowitz JD. Metabolic control of methylation and acetylation. Curr Opin Chem Biol. 2016;30:52-60. https://doi.org/10.1016/j.cbpa.2015.10.030

50. Yang H, Shan W, Zhu F, Wu J, Wang Q. Ketone Bodies in Neurological Diseases: Focus on Neuroprotection and Underlying Mechanisms. Frontiers in neurology. 2019;10:585. https://doi. org/10.3389/fneur.2019.00585

51. Pluta R, Ułamek-Kozioł M. The role of degenerative pathways in the development of irreversible consequences after brain ischemia. Neural Regen Res. 2019;14(6):982-983. https://doi. org/10.4103/1673-5374.250574

52. Pluta R, Ułamek-Kozioł M, Kocki J, Bogucki J, Januszewski S, Bogucka-Kocka A, et al. . Expression of the Tau Protein and Amyloid Protein Precursor Processing Genes in the CA3 Area of the Hippocampus in the Ischemic Model of Alzheimer's Disease in the Rat. Mol Neurobiol. 2020;57(2):1281-1290. https://doi.org/10.1007/s12035-019-01799-z

53. Stetler RA, Leak RK, Gan Y, Li P, Zhang F, Hu X, et al. Preconditioning provides neuroprotection in models of CNS disease: paradigms and clinical significance. Prog Neurobiol. 2014;114, 58-83. https://doi.org/10.1016/j.pneurobio.2013.11.005

54. Kovalska M, Kovalska L, Pavlikova M, Janickova M, Mikuskova K, Adamkov M, et al. . Intracellular signaling MAPK pathway after cerebral ischemia-reperfusion injury. Neurochem Res. 2012;37: 1568-1577. https://doi.org/10.1007/s11064-012-0752-y

55. Buffo A, Rolando C, Ceruti S. Astrocytes in the damaged brain: molecular and cellular insights into their reactive response and healing potential. Biochem Pharmacol. 2010;79:77-. https://doi. org/10.1016/j.bcp.2009.09.014

56. Zhang QG, Wang RM, Han D, Yang LC, Li J, Brann DW. Preconditioning neuroprotection in global cerebral ischemia involves NMDA receptor-mediated ERK-JNK3 crosstalk. Neurosci Res. 2009;63(3):205-212. https://doi.org/10.1016/j.neures.2008.12.010 
57. Zhou J, Du T, Li B, Rong Y, Verkhratsky A, Peng L. Crosstalk between MAPK/ERK and PI3K/ AKT signal pathways during brain ischemia/reperfusion. ASN Neuro. 2015;20:1-16. https://doi. org/10.1177/1759091415602463

58. Tyagi N, Qipshidze N, Munjal C, Vacek JC, Metreveli N, Givvimani S, et al. Tetrahydrocurcumin ameliorates homocysteinylated cytochrome-c mediated autophagy in hyperhomocysteinemia mice after cerebral ischemia. J Mol Neurosci. 2012;47:128-138. https://doi.org/10.1007/s12031-011-9695-z

59. Alam MM, Mohammad AA, Shuaib U, Wang C, Ghani U, Schwindt B, et al. Homocysteine reduces endothelial progenitor cells in stroke patients through apoptosis. J Cereb Blood Flow Metab. 2009;29:157-165. https://doi.org/10.1038/jcbfm.2008.99

60. Yang Z, Wang L, Zhang W, Wang X, Zhou S. Plasma homocysteine involved in methylation and expression of thrombomodulin in cerebral infarction. Biochem Biophys Res Commun. 2016;473: 1218-1222. https://doi.org/10.1016/j.bbrc.2016.04.042

61. Caldeira MV, Salazar IL, Curcio M, Canzoniero LM, Duarte CB. Role of the ubiquitin-proteasome system in brain ischemia: friend or foe? Prog Neurobiol. 2014;112:50-69. https://doi.org/10.1016/j. pneurobio.2013.10.003

62. Toda N, Okamura T. Hyperhomocysteinemia impairs regional blood flow: involvements of endothelial and neuronal nitric oxide. Pflugers Arch. 2016;468:1517-1525. https://doi.org/10.1007/ s00424-016-1849-y

63. Soares MSP, de Mattos BdS, de Souza AÁ, Spohr L, Tavares RG, Siebert C, et al. hypermethioninemia induces memory deficits and morphological changes in hippocampus of young rats: implications on pathogenesis. Amino Acids. 2020;52:371-385. https://doi.org/10.1007/s00726-019-02814-2

64. Suzuki S, Kodera Y, Saito T, Fujimoto K, Momozono A, Hayashi A, Kamata Y, Schichiri M. Methionine sulfoxides in serum proteins as potential clinical biomarkers of oxidative stress. Sci Rep. 2016; 6:38299. https://doi.org/10.1038/srep38299

65. Stefanello FM, Matté C, Scherer EB, Wannmacher CMD, Wajner M, Wyse ATS. Chemically induced model of hypermethioninemia in rats. J Neurosci Methods. 2007;160:1-4. https://doi.org/10.1016/j. jneumeth.2006.07.029

66. Hainsworth AH, Yeo NE, Weekman EM, Wilcock DM. Homocysteine, hyperhomocysteinemia and vascular contributions to cognitive impairment and dementia (VCID). Biochim Biophys Acta. 2016;1862:1008-1017. https://doi.org/10.1016/j.bbadis.2015.11.015

67. Low A, Mak E, Rowe JB, Markus HS, O'Brien JT. Inflammation and cerebral small vessel disease: A systematic review. Ageing Res Rev. 2019;53:100916. https://doi.org/10.1016/j.arr.2019.100916

68. Rizk T, Turtzo LC, Cota M, Van Der Merwe AJ, Latour L, Whiting MD, Chan L. Traumatic microbleeds persist for up to five years following traumatic brain injury despite resolution of other acute findings on MRI. Brain Injury. 2020;34(6):773-781. https://doi.org/10.1080/02699052.2020.1725835

69. Ding GL, Chopp M, Li L, Zhang L, Zhang ZG, Li QJ, Jian Q. Magnetic Resonance Imaging of Stroke in the Rat. Bo Pu Xue Za Zhi. 2014;31(1):116-132. https://doi.org/10.1016/j.neuroscience.2014.04.025

70. Hnilicová P, Kantorová E, Poláček H, Grendár M, Bittšanský M, Čierny D, et al. Altered hypothalamic metabolism in early multiple sclerosis-MR spectroscopy study. Journal of the Neurological Sciences. 2019, 407, 116458. https://doi.org/10.1016/j.jns.2019.116458

71. Lukaszevicz AC, Sampaïo N, Christelle Guégan C, Benchoua A, Couriaud C, Chevalier E, et al. High Sensitivity of Protoplasmic Cortical Astroglia to Focal Ischemia. J Cereb Blood Flow Metab. 2002;22:289-298. https://doi.org/10.1097/00004647-200203000-00006

72. Dossi E, Vasile F, Rouach N. Human astrocytes in the diseased brain. Brain Res Bull. 2018;136: 139-156. https://doi.org/10.1016/j.brainresbull.2017.02.001

73. Weekman EM, Woolums AE, Sudduth TL, Wilcock DM. Hyperhomocysteinemia-Induced Gene Expression Changes in the Cell Types of the Brain. ASN Neuro. 2017;9(6):1-11. https://doi.org/ $10.1177 / 1759091417742296$

74. Huang YC, Tzeng WS, Wang CC, Cheng BC, Chang YK, Chen HH, et al. Neuroprotective effect of agmatine in rats with transient cerebral ischemia using MR imaging and histopathologic evaluation. Magn Reson Imaging. 2013;31:1174-1181. https://doi.org/10.1016/j.mri.2013.03.026

75. Öz G, Alger JR, Barker PB, Bartha R, Bizzi A, Boesch C, et al. Clinical Proton MR spectroscopy in central nervous system Disorders. Radiology. 2014;270(3):658-79. https://doi.org/10.1148/radiol.13130531 
76. Ford J, Dogan N, Young L, Yang F. Quantitative Radiomics: Impact of Pulse Sequence Parameter Selection on MRI-Based Textural Features of the Brain. Contrast Media Mol Imaging. 2018;2018:1729071. https://doi.org/10.1155/2018/1729071

77. Harris JL, Choi IY, Brooks WM. Probing astrocyte metabolism in vivo: proton magnetic resonance spectroscopy in the injured and aging brain. Front Aging Neurosci. 2015;7:202. https://doi. org/10.3389/fnagi.2015.00202

78. Merali Z, Huang K, Mikulis D, Silver F, Kassner A. Evolution of blood-brain-barrier permeability after acute ischemic stroke. PLoS One. 2017;12(2):e0171558. https://doi.org/10.1371/journal. pone. 0171558

79. Huang WY, Wu G, Guo SX, Geng DY, Li JL, Yang K. Multi-parameters of Magnetic Resonance Imaging to estimate Ischemia-Reperfusion Injury after stroke in Hyperglycemic Rats. Scientific Report. 2019;9:2852. https://doi.org/10.1038/s41598-019-39263-6

80. Wang X, Cui L, Joseph J, Jiang B, Pimental D, Handy DE, Liao R, Loscalzo J. Homocysteine induces cardiomyocyte dysfunction and apoptosis through p38 MAPK-mediated increase in oxidant stress. J Mol Cell Cardiol. 2012;52:753-760. https://doi.org/10.1016/j.yjmcc.2011.12.009

81. Majumder A, Singh M, George AK, Homme RP, Laha A, Tyagi SC. Remote ischemic conditioning as a cytoprotective strategy in vasculopathies during hyperhomocysteinemia: An emerging research perspective. J Cell Biochem. 2018;120(1):77-92. https://doi.org/10.1002/jcb.27603

82. Wang PF, Xiong XY, Chen J, Wang YC, Duan, Yang, QW. Function and mechanism of toll-like receptors in cerebral ischemic tolerance: from preconditioning to treatment. J Neuroinflammation. 2015a;12:80. https://doi.org/10.1186/s12974-015-0301-0

83. Baranovicova E, Grendar M, Kalenska D, Tomascova A, Cierny D, Lehotsky J. NMR metabolomic study of blood plasma in ischemic and ischemically preconditioned rats: an increased level of ketone bodies and decreased content of glycolytic products $24 \mathrm{~h}$ after global cerebral ischemia. J Physiol Biochem. 2018;4(3):417-429. https://doi.org/10.1007/s13105-018-0632-2

84. Kalani A, Kamat PK, Tyagi SC, Tyagi N. Synergy of homocysteine, microRNA, and epigenetics: a novel therapeutic approach for stroke. Mol Neurobiol. 2013;48:157-168. https://doi.org/10.1007/ s12035-013-8421-y

85. Li JG, Barrero C, Gupta S, Kruger WD, Merali S, Praticò D. Homocysteine modulates 5-lipoxygenase expression level via DNA methylation. Aging Cell. 2017;16(2):273-280. https://doi.org/10.1111/ acel. 12550

86. Leon M, Sawmiller D, Shytle RD, Tan J. Therapeutic Cocktail Approach for Treatment of Hyperhomocysteinemia in Alzheimer's Disease. Cell Med. 2018;10:2155179017722280. https://doi. org/10.1177/2155179017722280 